SIR-We have recently received distressing news from colleagues at the University of Chile, Santiago. Over the past ten years, both the university budget and student numbers have been reduced by half and no positions have been opened for the recruitment of young scientists and teachers.

Last September, General Pinochet designated $\mathrm{Mr}$ José Federici as rector of the university without any prior consultation with the university council or the professors. This procedure was resented, and 11 out of 13 members of the university council (among them the elected faculty deans) considered that Mr Federici had no credentials to rule the university.

In response to this reaction of the council, Mr Federici dismissed the deans of four faculties: Professors Mario Mosquera (law), Atiliano Alamana (engineering), Fernando Valenzuela

\section{Refereeing reforms}

SIR-The council of the American Physical Society (APS) has recently issued a statement, "Integrity of physics" (Physics Today 40, 81; 1987) which lists the following six actions as "sinful": (1) plagiarism, (2) data fabrication and manipulation, (3) submission of the same paper or its trivial variations to more than one publication, (4) fictitious coauthorship, (5) a reviewer's lack of impartiality and (6) slow response of a referee in order to suppress the publication.

There can hardly be doubts about the correctness of Commandments 1, 2, 4, 5 and 6 , but I wonder about the third. Does it occur to the authors that this is in some contradiction with commandments 5 and 6? Under the existing refereeing system, the author of any innovative idea or experiment remains a helpless hostage of the anonymous referee(s) for an unspecified period of time. If, after some months, a paper is rejected (often almost without comment) the author has no means of claiming his priority - submission to another journal is a brand-new deal with, of course, a new submission date.

Simultaneous publication of exactly the same paper in two or more different jour nals is an embarrassing occurrence for the authors. Nobody wants this. Yet most people would agree that the simultaneous submission of 'trivial variations' of the same study to more than one journal is often the only practical way to reduce the risk of being victimized by the unfair refereeing system. This is especially true for a novice trying to enter a highly competitive area.

The solution which, I hope, many will find reasonable is the following. Major journals should promptly publish authors' abstracts of all submitted papers (unless (philosophy) and Hernan Montecinos (architecture). Moreover, Mr Federici closed the university, impeding access by the professors, students, researchers and technicians to the university premises, thus interrupting the development of research programmes in progress. More recently, Mr Federici dismissed 35 other professors from various faculties, some of them members of the council of the Professors' Association; 150 students were also expelled. The dismissal of the professors was a flagrant violation of the tenure system instituted in recent years.

Criticism has mounted to the point where Mr Federici was replaced by a new rector, Professor Juan de Dios Vial, on 29 October. We hope that this encouraging development will give rise to a reversal of the repressive measures instituted by the government. Meanwhile, we feel that the

authors themselves instruct otherwise), leaving the acceptance of the full text subject to the usual refereeing. Length constraints and, possibly, an optional small charge could be applied. It would be for authors to ensure that their priority claims are properly expressed in the available space. I stress that the proposed system is not the same as the publication of abstracts in the APS Bulletin, for jour nals would publish only abstracts accompanied by full texts.

Alexander A. Berezin

Department of Engineering Physics,

McMaster University,

Hamilton, Ontario,

Canada, L8S 4MI

\section{Vatican and IVF}

SIR - In reaction to Henri Firket's letter (Nature 329, 100; 1987) on the Vatican condemnation of in vitro fertilization, I would like to make the following points.

Firket defends the elimination of surplus fertilized eggs (a by-product of in vitro fertilization) on the ground that this is a common process in nature. Let us, however, suppose that the Vatican is right in its assertion that a fertilized human ovum is a human being in the normal sense of the word, although in its earliest stage of development. It becomes clear, then, that its "elimination" cannot be excused by pointing to nature's eliminating other human beings in later stages of their development, as is happening now, for example, in Ethiopia. Ethically speaking, humans sometimes have to act in a quite different way from what happens in nature.

Second, if this destruction of fertilized ova brought about by nature is necessary for the maintenance of the "genetic quality of the species", is maintaining this quality the aim of people who destroy international scientific community may be able to help our Chilean colleagues in their efforts to defend academic freedom and scientific research in Chile. With this purpose in mind, we ask the members of the scientific community to make known their opposition to the university closure and the abusive dismissal of the professors of the University of Chile by sending letters to the following: Professor Juan de Dios Vial, Rector, Universidad de Chile, Avenida Libertador Bernardo O'Higgins 1371, Santiago, Chile and $\mathrm{Mr}$ Juan Antonio Guzman, Ministro de Educación Pública, at the same address.

Alexander Mauro

The Rockefeller University,

1230 York Avenue,

New York, New York 10021, USA

Hersch M. Gerschenfeld

Laboratoire de Neurobiologie,

Ećole Normale Supérieure,

46 Rue d'Ulm,

75230 Paris Cedex 05, France

\section{surplus fertilized ova?}

Third, there is a passage I do not understand: "When this destruction of potential human life [the Vatican would say: leave out 'potential'] takes place as early as possible, it leads to a reduction of the total amount of suffering." Whose suffering? If the potential suffering of the unborn human being is meant, we are speaking about euthanasia in its earliest possible stage. If, however, the suffering of the survivors, who will experience the effects of population explosion, is meant, it does not explain why they have the right to live at the expense of other humans.

We must first decide whether a fertilized ovum is a human or not before we can talk about how to dispose of it. Until then, we should not dismiss the Vatican's view.

Vermeerstraat 18

E. J. BONESCHANSCHER

3817 De Amersfoort,

The Netherlands

\section{Genome sequencing}

SIR - Further to David Tepfer's all too legitimate list of questions about the source of the sequenced human genome (Nature 329, 480; 1987), add the following. Should the person be male or female? Should he/she be alive or freshly dead (how much tissue do the molecular biologists need - an arm, a leg ... ?) Should he/she be identified? Should candidates on the short list be screened for absence of heritable diseases?

And the most terrifying question of all, who is to decide?

Institue für Hormon und Martin LuCK

Fortpflanzungsforschung,

Grandweg 64,

2000 Hamburg 64, FRG 